\title{
How Much Do Core Journals Change over a Decade?
}

\section{The Case of Communication Disorders}

\section{Steve Black}

This study replicates the method of identifying core journals in the field of communication disorders published in the January 2001 issue of Library Resources and Technical Services for the purpose of determining the degree to which the ranked list changed after ten years. Two measures are used to assess the reliability of rankings over time: Spearman's rho rank correlations among the citing journals and coefficients of variation among cited journals. Rank correlations of groups of journals can mask important changes in rank for individual titles, so characteristics of the journals with the greatest movements in rank over a decade are explored. Major findings are that the discipline's literature grew substantially over the decade, and the core journals remained stable over ten years $\left(r_{\mathrm{s}}=0.73\right)$. However, despite stability of core journals over time, some titles changed dramatically in rank. Coefficients of reliability calculated for this group of communication disorders journals suggests that approximately one-third of observed change in ranks is because of random variability in works cited.

Steve Black (blacks@strose.edu) is Serials and Reference Librarian, Neil Hellman Library, The College of Saint Rose, Albany, New York.

Submitted December 6, 2011; tentatively accepted, pending modest revision December 15, 2011; revisions submitted December 22, 2011, and accepted for publication.

The author thanks Stan Lyle at the Rod Library, University of Northern lowa, for sending the article count for the 1997 volume of Journal of Medical SpeechLanguage Pathology.
$\mathrm{T}$ he January 2001 issue of Library Resources and Technical Services (LRTS) published an article by this author on core journals in the field of communication disorders. ${ }^{1}$ The purpose of the present study is to determine the degree to which the ranked list of frequently cited journals in communication disorders changed after ten years. Because serials collection development relies on choosing the most relevant journals among many, keeping track of changes in core journals over time is vital. An important related question is whether changes in rank observed over time were greater than variation in ranks between titles covering the same years. This is important because reliability (consistency of measurements) indicates whether changes in rank are indicative of journals' true rise or fall relative to others or the result of random movement caused by measuring different samples. Two measures are used to assess the reliability of rankings over time: rank correlations among the citing journals and coefficients of variation among cited journals. Correlations of journal rankings provide a useful measure of the reliability of core lists over time, but looking at journals as a group can mask important changes in the ranks of individual titles. Therefore this study includes a look at the characteristics of journals that experienced the greatest movement up or down the ranked list of most frequently cited journals in the field of communication disorders. 


\section{Literature Review}

In her conclusion to a 2003 overview of journals in communication disorders, Shpilko recommended that future researchers use citation analysis to follow trends in the literature because core journals are likely to change over time. ${ }^{2}$ Various criteria (including lists compiled by subject experts, extent of coverage by indexes, library holdings, surveys of faculty, and citation data) for selecting the best journals to support research within a discipline have been used by collection development librarians. ${ }^{3}$ Citation analysis is the study of relationships between authors, articles, journals, concepts, institutions, nations, and other elements by compiling and counting references in documents. ${ }^{4}$ Broadly stated, citation analysis is the study of relationships among published works based on the principle that a reference in a published paper implies a relationship between the cited and the citing documents. ${ }^{5}$ One type of citation analysis is to count citations to identify leading journals in a discipline. The present study employed the method of counting citations to identify the most frequently cited journals in a discipline, in this case communication disorders.

\section{Using Published Impact Factors to Rank Journals}

Garfield's pioneering work, comparing citation counts to objectively evaluate the relative quality of journals on the basis of how frequently they are referenced, led to the creation of the Institute for Scientific Information's (ISI) citation indexes. ${ }^{6}$ The citation indexes are now incorporated within Thomson Reuters' Web of Knowledge, which also includes Journal Citation Reports, a ranking of journals by topic area based on impact factors. A journal's impact factor is calculated "by dividing the number of current year citations to the source items published in that journal during the previous two years." ${ }^{.7}$ The journal impact factors published by Thomson Reuters have become standard, albeit controversial, metrics for the measurement of importance or quality of journals, authors, and institutions. A voluminous literature has critiqued the methods of formulating impact factors and the (mis)applications of them in various contexts. A small but representative sample of these critiques are reviewed here to highlight primary concerns surrounding the validity and reliability of impact factors as calculated in the Web of Knowledge.

One line of criticism points out logical and practical weaknesses in the very concept of using impact factors to judge journals, scholars, or institutions. Martin emphasized the need for a conceptual distinction between the quality, importance, and impact of publications and cautioned that citation counts are only useful as a measure of impact. ${ }^{8} \mathrm{He}$ wrote in the context of assessing the output of research centers, but his logic applies equally well to journals. In his view, quality is how well the research is conducted and written, importance is the potential influence of the work, and impact is the actual influence. Importance and impact are closely related, but it takes time for importance to be reflected in citations, and for reasons such as language, prominence of the journal in which it was published, or narrowness of subspecialty, an important paper may receive few citations. Simply put, a high-quality paper may have the misfortune of never receiving much attention.

Rosenstreich and Wooliscroft wrote a particularly good summary of critiques of citation-based journal rankings. ${ }^{9}$ The critiques include arguments that frequency of citation is not equal to quality because a "halo effect" raises the profile of a journal containing a highly cited paper, and a "Matthew Effect" causes highly cited papers to continue to be more visible and thus more highly cited. The halo effect occurs when a highly cited article draws attention to other articles in the same issue of a journal, a phenomenon that is becoming less prevalent as more articles are viewed online in isolation from others published within an issue..$^{10}$ The Matthew Effect was coined by Merton after the passage in Matthew (13:12), "for unto every one that hath shall be given, and he shall have abundance: but from him that hath not shall be taken away even that which he hath."11 The more attention something receives, the more attention it will continue to receive. The presumption is that this Matthew Effect skews citation rates because the most highly cited papers or journals end up receiving more citations than they deserve based solely on their quality and importance. An issue related to such skewed citation is Seglen's point that little correlation exists between the quality of a paper and the quality of the journal that published it. He argues that because excellent papers appear in lesser-known journals, those judging a researcher's work should not consider the impact factors of the journals in which they have published. ${ }^{12}$

Much of the literature critiquing journal rankings specifically addressed perceived shortcomings in the data published by the Institute for Scientific Information (ISI). MacRoberts and MacRoberts described several problems with ISI's method of ranking journals in the Journal Citation Reports: influences not being cited, biased citing, inappropriate self-citation, no distinctions between negative and positive references, variation in citation patterns among disciplines, miscounts due to misspellings, multiple authors with the same name, and incomplete coverage of the literature. $^{13}$ One should note that Thomson Reuters is aware of such critiques and works to minimize those errors they are able to control. ${ }^{14} \mathrm{~A}$ criticism of the Thomson Reuters citation data unrelated to the aforementioned issues is the high cost. Purdue and Piotrowski note that many researchers have budgets that are insufficient to gain access to the data. ${ }^{15}$ 


\section{Ranked Lists Created Independently from Published Impact Factors}

Since counting citations is an objective way to measure the impact of journals, but citation data published by Thomson Reuters have drawbacks, researchers have created rankings of journals using other sources of citation data. Studies based on data from sources other than the Web of Knowledge are particularly useful for measuring the impact of journals in multidisciplinary fields. This is because the field may not be a category in Thomson Reuters' Journal Citation Reports (JCR) and data on journals covered by JCR reflect citations from all disciplines. For example, the published impact factor for Library Resources and Technical Services makes no distinction among citations from papers in library science, management, or any other discipline. That may be of little concern in well defined and established disciplines, but measuring only citations from within the discipline is essential for determining the most frequently cited journals in new, multidisciplinary fields. Without a focused analysis, one cannot know the degree to which the published impact factor correlates with the real impact of a journal within a specific field such as communication disorders.

One approach for an independent study is to use citation index data but not rely on the JCR. In 1991 when the citation indexes were available as dial-up databases, McCain employed the Cited Work field in the online version of Science Citation Index (SCISEARCH) to identify core journals in genetics. ${ }^{16}$ Other researchers have chosen to count citations independently rather than rely on citation indexes. Independent studies may be global (measure citations published anywhere) or local (measure citations of publications by researchers from one institution, state, or nation). Because the present paper is based on citations published anywhere, only global citation analysis studies will be noted here. Kushkowski, Gerhard, and Dobson advocated using a Simple Index Method to aid collection development librarians in their decision making. ${ }^{17}$ The Simple Index Method generates ranked lists of core journals in a topic area by counting citations to journals in indexes such as Econlit, ABI/Inform, or PsycINFO. Mack created a list of core women's studies journals by counting citations in Signs, a journal known to be prominent in that discipline, and concluded that citation analysis was superior to surveying faculty for identifying core journals. ${ }^{18}$ Sittig culled citation data from the Medline bibliographic database to identify top journals in the interdisciplinary field of medical informatics. ${ }^{19}$ Goss counted citations from textbooks and journals to rank top journals in optometry and ophthalmology. ${ }^{20}$ Wray began with a set of five source journals to identify core journals in special education. ${ }^{21}$ Slater created a ranked list of journals in speech-language pathology by counting citations in the 1991-93 issues of American Journal of Speech-Language
Pathology, Journal of Speech and Hearing Research, European Journal of Disorders of Communication, and Journal of Communication Disorders. ${ }^{22}$ Slater's study was similar enough to the present work to draw comparisons and calculate correlations, so it will be referred to again below.

Despite these examples of independent work, the preponderance of journal rankings has been based on data published by Thomson Reuters or Elsevier. Thomson Reuters' Web of Knowledge is the best-known source, but impact factors also are available in Elsevier's Scopus, and citation analysis of ever-increasing sophistication can be accomplished with Google Scholar. In fact, Harzing and van der Wal argue that Google Scholar is a superior data source because it has the most comprehensive coverage of journals. ${ }^{23}$

\section{Reliability of Journal Rankings}

Perhaps because of the widespread use of the Web of Knowledge, surprisingly little has been written about the reliability of journal rankings that are based on citation counts. Variation exists over time and because of sample selection, but very few published studies have addressed the degree of variation. Variability in what is cited has been recognized for a long time. Bradford's seminal 1934 article on a discipline's concentration of citations in a core of journals includes a discussion of the marked variability of journals cited from journals outside the core. ${ }^{24}$ He noted that the number of journals cited at least once grows linearly with the period of years being surveyed. The fact that more journals are cited as sample size increases is evidence for a fundamental variability in what is being cited. Nieuwenhuysen and Rousseau modeled which elements of fluctuation in citations were due to random variation rather than a genuine rise or decline in citations received by a journal..$^{25}$ Their model was based on the coefficient of variation of total citations received and the journals' impact factors. They found that the rank of a journal high on a list can be expected to vary little over time, but that the rank of a journal lower on a list will fluctuate more in rank. This is because at lower citation rates, a relatively small change in times cited causes a relatively large change in rank. Line noted that, over time, the reliability of a journal's rank grows weaker as one moves down a list, stating "it is a matter of chance whether a littleused or little-cited title receives, in any one year, zero, one, two, three, four, or five uses or citations, although the rank order may be dramatically affected." ${ }^{\text {26 }}$ Therefore he advocated that studies be conducted to measure the reliability of citation counts at the fringes of use. Line's point of view was based on his research that found limited commonality in journal rankings from the JCR with lending patterns at the British Library Lending Division in 1975, 1980, and 1983. Overlap in titles within the JCR lists over time was in the range of 80 percent to 95 percent, but overlap within 
serials requested by the British Library over time was in the range of 54 percent to 62 percent. In another article, Line speculated that the dramatic difference stemmed from less variation between serials used by researchers than variability between serials used by the borrowing public at large. ${ }^{27}$ Broadus acknowledged the difficulty in making judgments for low-use titles but maintained that, despite issues of reliability, JCR rankings were a cost-effective starting point for deciding which journal subscriptions to cancel. ${ }^{28}$

\section{Global versus Local Use}

A fundamental issue raised by Broadus' argument for using the JCR for collection development decision was the correlation of global use (citations in the published works measured by the $J C R$ ) versus local use by library patrons. ${ }^{29}$ Simply put, can JCR data reliably predict what a library's patrons will need? For an overview of studies that looked at the correlation of global with local use, see Kelland and Young. ${ }^{30}$ They note that citation is a useful evaluative tool even though faculty refer to journals beyond their library's collection and some uses of journals in the collection may go uncounted. A few studies of global versus local use have used rank correlation as the method for measuring the relationship. White and White correlated psychology journal rankings in the Social Science Citation Index with rankings by subjective evaluation by psychologists, finding Spearman rank correlations of $r_{\mathrm{s}}=0.39$ and $r_{\mathrm{s}}=0.56$. $^{31}$ Ralston, Gall, and Brahmi correlated ranked lists of psychiatry journals to determine how reliably JCR data matched works cited in publications by faculty of the Indiana University School of Medicine and found a strong positive rank correlation of $r_{\mathrm{s}}=0.79$, concluding that the global JCR data effectively captured local psychiatry research emphases. ${ }^{32}$ Kreider compared works cited by faculty publications at the University of British Columbia with the JCR and found strong positive correlations for most disciplines. ${ }^{33}$

\section{Statistical Tests for Ranked Lists}

Kreider performed logarithmic transformations on the data and then correlated results using Pearson's product-moment coefficients based on the advice of Bensman that such an approach was a superior way to analyze citation data. ${ }^{34} \mathrm{He}$ argued correctly that Pearson's product-moment coefficients are based on parameters that include a normal distribution. But citation data are virtually always highly skewed and thus better modeled by a negative binomial distribution, e.g., Bradford's Law of Scattering. ${ }^{35}$ Other solutions besides logarithmic transformations address this problem. Lack of fit to a standard distribution is the reason nonparametric tests were developed that are not based on assumptions about the population being measured. Such nonparametric statistics include the well-known and widely used Spearman rank correlation test of the degree of association between two sets of data listed in rank orders. ${ }^{36}$ The nonparametric Spearman's rho $\left(\right.$ denoted $r_{s}$ ) is an appropriate measure for correlating ranked lists because it is not based on assumptions (parameters) regarding normal distribution or standard variation of numerical data. ${ }^{37}$ The Merriam-Webster dictionary defines reliability as "the extent to which an experiment, test, or measuring procedure yields the same results on repeated trials. ${ }^{\text {"38 }}$ Spearman's rho is the appropriate tool for determining the reliability of ranked lists because it measures the degree of association between two sets of data, whether the sets are from different samples taken within the same time period or from comparable samples taken at different times.

\section{Method}

Half of the data for this study come from the author's 2001 LRTS article on a core collection in communication disorders. To determine the degree to which the core list changed over a decade, works cited were compiled for the appropriate volumes of the two journals used in the initial study: Journal of Speech, Language, and Hearing Research (JSLHR) and Journal of Communication Disorders (JCD). The broader sample of four journals used by Slater may better represent the literature, but the sample corresponding to this author's first study was used to minimize extraneous variables. ${ }^{39}$ The volumes, number of articles published, number of works cited, and average number of works cited per article are shown in table 1.

For the 2001 study the author entered the data by hand from printed issues. Thankfully, new tools are now available to speed the process of compiling works cited. The journals used for this study are covered by the PsycINFO bibliographic database. PsycINFO has the very useful feature of including the works cited of every article whether the full text is available or not. The author exported the works cited from every issue of the sampled journals from PsycINFO (via EBSCOhost) into the Refworks bibliographic management program. A drawback of downloading works cited instead of entering them by hand is that PsycINFO tags works from any type of series as "journal article." The author was thus unable to re-create the proportion of citations from journals, conferences, tests, books, and others that appeared in figure 1 of the 2001 study. ${ }^{40}$ Databases hosted by EBSCO can export directly into several bibliographic management programs, any of which could be used for compiling citation data. RefWorks was chosen as the most cost-effective choice. Exported citations were organized into one folder for each volume of each journal, and each folder was downloaded into a Microsoft Excel worksheet. Keeping data from each volume discrete allowed the analysis that appears in table 2 . 
Table 1. Journals in Communication Disorders and Growth in Scholarly Literature

\begin{tabular}{lcc}
\hline Journals Used for This Study & Articles Published & \multicolumn{2}{c}{$\begin{array}{c}\text { Average Works Cited } \\
\text { per Article }\end{array}$} \\
Journal of Communication Disorders 1997-99 & 76 & 2,756 \\
Journal of Speech, Language, and Hearing Research 1997 & 103 & 4,336 \\
Journal of Speech, Language, and Hearing Research 1999 & 103 & 4,714 \\
Journal of Communication Disorders 2007-9 & 102 & 4,785 \\
Journal of Speech, Language, and Hearing Research 2007 & 109 & 5,407 \\
Journal of Speech, Language, and Hearing Research 2009 & 117 & 5,439
\end{tabular}

Table 2. Spearman's rho $\left(r_{s}\right)$ Rank Correlation Coefficients among the Six Volumes

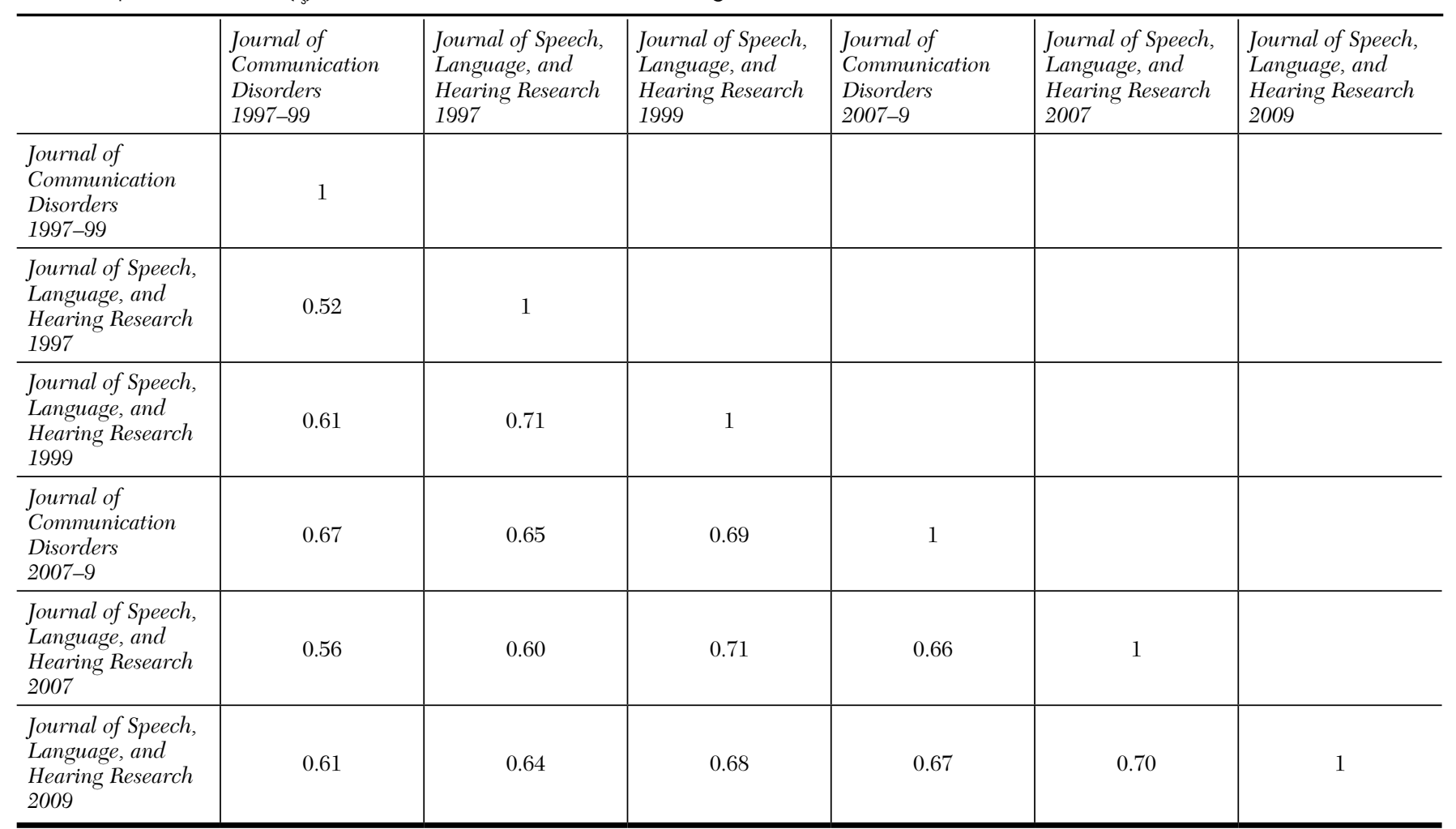

The author used Excel to compile and analyze the works cited data from the six journals. A time-consuming but important task was fixing discrepancies in titles. For example, title variants Audiol Neurootol, Audiol Neurotol, Audiology \& Neuro-Otology, Audiology \& Neurotology, and Audiology and Neuro-Otology were edited to match the title as it appears in OCLC WorldCat, Audiology of Neuro-otology. Even with careful editing, the author deemed alphabetizing lists and counting citations to be better rather than relying on Excel's COUNTIF function, because any overlooked discrepancy in punctuation or spelling could cause a citation to go uncounted. Citations to books, standards, tests, chapters in series, and anything other than citations to journals were ignored. Title changes posed something of a dilemma. Does the new title count as a new work to be treated separately or as a continuation of the same work? The author chose to aggregate counts for journals that changed title, but the author treated splits and mergers as separate works.

Counts for journals cited at least 5 times were copied to a separate worksheet for each citing journal. Worksheets were created to aggregate results by decade, one for 1997-99 and one for 2007-9. All lists were sorted by citation count to create ranked lists of cited journals. The core list published in 2001 included 104 journals that represented 80 percent of citations to journals. This base was used to establish 104 as the maximum number of journals in the ranked lists used here. 


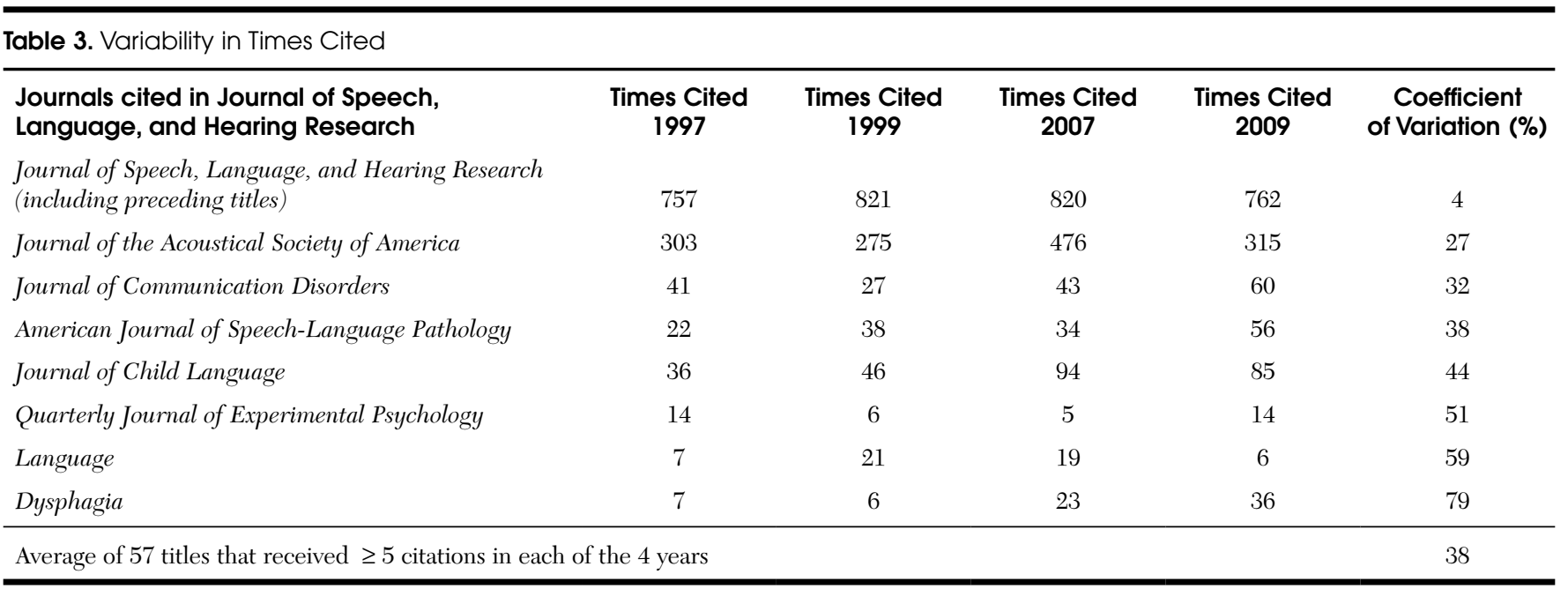

The Spearman's rho rank coefficient statistical test was used to measure whether rankings vary more over time than they do between the titles. The data for each pair of journals shown in table 2 were assigned ranks. For example, articles in the JCD 1997-99 had 89 journals cited at least 5 times. Many of these received an equal number of citations, but to calculate $r_{s}$, one must have 89 ranks for 89 journals. Ties were summed and averaged, e.g., 2 titles receiving 19 citations each were both ranked 16.5, and 6 titles receiving 11 citations were each ranked 34.5. Each pair of ranked lists included titles with no match. The nonmatched titles were given a rank one below the bottom. For instance, when correlating with the ranked list of 89 titles from JCD 1997-99, journals from the other lists that did not match were ranked 90. The correlations of ranked lists are shown in table 2 .

Calculating rank correlations is a valid way to measure reliability; analyzing data from more than one perspective can be helpful. Another way to examine whether rankings vary more over time than they do between the titles is to calculate coefficients of variation. Coefficient of variation is the standard deviation divided by the mean. Standard deviation is only meaningful in the context of sample size as a measure of the dispersal of scores. Dividing standard deviation by the mean produces a relative dispersal that allows comparison of the spread of scores among different sample sizes. ${ }^{41}$ Coefficients of variation were calculated for the cited journals appearing in all four ranked lists from the volumes of JSLHR. The average variation and examples representing the range of variation are shown in table 3 .

The formula for Spearman's rho takes into account journals that change dramatically in rank. But because it treats subjects as a group, the statistical measure can obscure significant changes at the level of individual journals. To account for this, journals that moved most in rank between 1997-99 and 2007-9 were identified and scrutinized. Myriad characteristics might affect the impact of a journal. The author chose to investigate dates of publication, publisher, number of articles published in 1997, number of articles published in 2009, price, and availability online. The author retrieved dates of publication from WorldCat and determined publishers from the journals' websites. Article counts came from databases including Medline, PsycINFO, and Communication and Mass Media Complete, with the exception of Journal of Medical Speech-Language Pathology, which was determined by examining the journal. The author used EBSCOnet to look up prices. For purposes of comparison the author used prices for print subscriptions when available. For titles with tiered or otherwise differentiated pricing, subscription prices applicable to a masterslevel college were recorded. Online availability was found in EBSCOnet and confirmed from Serials Solutions' data, searching in the identified databases, and checking publishers' websites.

\section{Results}

The comparison of works cited between 1997-99 and 2007-9 shows growth in both the number of articles published per volume and the number of works cited per article. The most obvious case of growth in the literature is JCD's substantial increase in both the number of articles published and the average number of works cited per article. The JSLHR also experienced growth in articles and works cited. The sample as a group experienced a 32 percent increase in works cited over the decade.

The list of most frequently cited journals for 2007-9 from the JSLHR and JCD is shown the appendix. The sample contained 15,631 works cited, a total that includes citations to books, conferences, tests, and other resources. Ranks are based on the percentage of citations received, and the rightmost column indicates the change in rank relative to 
the 2001 list of 104 journals representing 80 percent of citations to journals. ${ }^{42}$ The method of downloading works cited from PsycINFO obscured the type of resource being cited, so the percentages of works cited shown in the appendix total less than 80 percent. Titles that were not on the list of 104 titles published in 2001 were assigned a rank of 104, thus counting them as ties for last place. The Spearman rank correlation coefficient of the 1997-99 ranks against the 2007-09 ranks is $r_{\mathrm{s}}=0.73$. In essence, the Spearman correlation formula squares the differences in rankings and divides that by how many items are being ranked. By design, dramatic changes in rank by many items in the measured group will cause $r_{s}$ to approach zero, i.e., no relationship between the two ranked lists. No changes in rank between lists would result in $r_{s}=1$, a perfect correlation and total reliability between the two measurements. Any coefficient above 0.70 is generally considered a very strong positive correlation that indicates a high degree of reliability. However, the $r_{\mathrm{s}}=0.73$ must be considered within the context of two key factors: random variability in the journals authors cite and possible variation due to the composition of the sample.

Some of the change in which journals are cited is due to random variability. This makes determining the degree to which changes in rank are due to real changes in the literature or simply due to natural variability in which journals authors choose to cite difficult. Table 2 shows reliability of ranked lists among the volumes comprising the sample. As one might intuitively expect, the strongest correlations are between volumes of the same journal. Reliability as measured by Spearman's rho rank correlations for volumes of JSLHR range from $r_{\mathrm{s}}=0.60$ for the 1997 and 2007 volumes to $r_{s}=0.71$ for both 1997-99 and 1999-2007. The weakest correlations are for the 1997-99 volumes of the JCD. This may be due to differences in topic coverage, but is likely because JCD 1997-99 contained the fewest number of works cited. The smaller sample size may have caused the lower reliability. Striking is that the strong positive $r_{\mathrm{s}}=0.73$ between the entire 1997-99 and 2007-9 groups indicates greater reliability than exists from any of the volumes shown in table 2. In that context, the simplest answer to the question "how much does the core change over a decade?" is "not much." In fact, the between-group correlation of $r_{s}=$ 0.73 compared to the within-group correlations shown in table 2 allows one to reasonably infer that most of the measured change in core journals over one decade was due to random variability.

The effect of composition of the sample can be inferred from the correlations shown in table 2. Each volume represents its own sample, so one can see that the reliability of ranked lists from these six samples ranges from $r_{s}=0.52$ to $r_{\mathrm{s}}=0.71$, all indicators of strong, but not perfect, correlations. Another way to analyze the effect of sample selection is to compare these results to Slater's list of frequently cited journals in communication disorders. ${ }^{43}$ Slater used a method very similar to this authors' except that her sample was based on four journals. In addition to JSLHR and JCD, she also counted works cited in the American Journal of SpeechLanguage Pathology and the British Journal of Disorders of Communication/European Journal of Disorders of Communication. The period for Slater's study was 1991 through 1993. The correlation coefficients for Slater's results versus the present results are $r_{\mathrm{s}}=0.54$ for the 1997-99 list and $r_{\mathrm{s}}$ $=0.38$ for the 2007-9 list. The difference in samples makes it difficult to determine how much of the drop in reliability is because of true changes in the literature. However, the fact that reliability of ranked lists drops from $r_{\mathrm{s}}=0.54$ after six years to $r_{s}=0.38$ after sixteen years suggests a continual, albeit rather gradual, change in core journals over time.

Spearman's rho measures reliability on the basis of correlations of ranked lists. Another way to look at the degree of variability is to calculate coefficients of variation using the method explained above. Because the scope of $J C D$ is somewhat different from that of $J S L H R$, only ranked lists from $J S L H R$ were used for this analysis. Fifty-seven cited journals appeared on all four rankings from the volumes of JSLHR. As shown in table 3 , the average coefficient of variation was 38 percent. One can infer from this that roughly one-third of the variation in times cited is because of random variation. But this too varies, from the highly reliable 4 percent rate for the top journal to the very unpredictable 79 percent for Dysphagia. One sees a general trend for the most-cited journals to have the lowest coefficients of variation. That would come as no surprise to Line, who emphasized the difficulty of predicting use of journals on the fringe of a core. ${ }^{44}$

A reliability coefficient of $r_{\mathrm{s}}=0.73$ indicates that the core list of communication disorders journals changed relatively little over a decade, but this does not mean ranks of individual titles all stayed about the same. Table 4 shows the 10 journals that moved up the most in rank and selected characteristics that might suggest reasons for the changes. Trends in Cognitive Sciences and Developmental Science changed for the obvious reason that they were new launches. Length of time in publication also could be a major reason for increased citations to Journal of Medical Speech-Language Pathology, NeuroImage, and Psychological Science.

The case of the Journal of Medical Speech-Language Pathology is very interesting. It defies conventional wisdom to become so well established in the discipline despite being published only in print by a smaller publisher. Moreover, it is only indexed in Cumulative Index to Nursing and Allied Health Literature and Linguistics Language and Behavior Abstracts, not in the commonly used databases for communication disorders such as Medline, or PsycINFO, or Communication and Mass Media Complete. This shows that researchers manage to find their way to highly relevant 


\begin{tabular}{|c|c|c|c|c|c|c|c|}
\hline Title & $\begin{array}{l}\text { Rank } \\
\text { Change }\end{array}$ & $\begin{array}{l}\text { Pub. } \\
\text { Dates }\end{array}$ & Publisher & $\begin{array}{l}\text { Articles } \\
1997\end{array}$ & $\begin{array}{l}\text { Articles } \\
2009\end{array}$ & Price & Online \\
\hline Trends in Cognitive Sciences & +76 & $1997-$ & Elsevier & 109 & 80 & $\$ 2,043$ & ScienceDirect \\
\hline $\begin{array}{l}\text { Journal of Medical Speech-Language } \\
\text { Pathology }\end{array}$ & +63 & $1993-$ & Delmar & 25 & 19 & $\$ 177$ & no (published in print only) \\
\hline Language and Cognitive Processes & +60 & $1985-$ & $\begin{array}{l}\text { Taylor \& } \\
\text { Francis }\end{array}$ & 34 & 69 & $\$ 2,013$ & $\begin{array}{l}\text { with } 12 \text {-month embargo in } \\
\text { Communication \& Mass Media } \\
\text { Complete }\end{array}$ \\
\hline Journal of Neuroscience & +57 & $1981-$ & $\begin{array}{l}\text { Society for } \\
\text { Neuroscience }\end{array}$ & 897 & 1595 & $\$ 4,240$ & $\begin{array}{l}\text { OA after 6-month } \\
\text { embargo }\end{array}$ \\
\hline $\begin{array}{l}\text { Proceedings of the National Academy } \\
\text { of Sciences of the United States of } \\
\text { America }\end{array}$ & +52 & $1915-$ & $\begin{array}{l}\text { National } \\
\text { Academy of } \\
\text { Sciences }\end{array}$ & 2681 & 4026 & $\$ 2,150$ & OA after 6-month embargo \\
\hline Journal of Applied Physiology & +50 & $1985-$ & $\begin{array}{l}\text { American } \\
\text { Physiological } \\
\text { Society }\end{array}$ & 554 & 621 & $\$ 1,425$ & $\begin{array}{l}\text { OA after 1-year embargo, plus } \\
\text { "Author Choice" OA option }\end{array}$ \\
\hline NeuroImage & +47 & $1992-$ & Elsevier & 61 & 745 & $\$ 2,483$ & ScienceDirect \\
\hline $\begin{array}{l}\text { Cleft Palate Journal + Cleft Palate- } \\
\text { Craniofacial Journal }\end{array}$ & +44 & $\begin{array}{l}1964-90 \\
+1991-\end{array}$ & $\begin{array}{l}\text { American } \\
\text { Cleft Palate- } \\
\text { Craniofacial } \\
\text { Association }\end{array}$ & 84 & 100 & $\$ 347$ & $\begin{array}{l}\text { Publisher's website by subscrip- } \\
\text { tion,1964- } 89 \text { free from U Pitt } \\
\text { Digital Library }\end{array}$ \\
\hline Psychological Science & +38 & $1990-$ & Sage & 85 & 236 & $\$ 5,538$ & $\begin{array}{l}\text { Publisher's website by } \\
\text { subscription }\end{array}$ \\
\hline Developmental Science & +35 & $1998-$ & $\begin{array}{l}\text { Wiley- } \\
\text { Blackwell }\end{array}$ & $\mathrm{n} / \mathrm{a}$ & 117 & $\begin{array}{l}\$ 1,203 \\
\text { (online) }\end{array}$ & $\begin{array}{l}\text { Academic Search Premier after } \\
\text { 1-year embargo }\end{array}$ \\
\hline
\end{tabular}

literature. That also could be an explanation for the success of Cleft Palate-Craniofacial Journal. A possible factor in the success of those two journals is their relatively low subscription prices.

The remaining titles on the list of journals with greatest increases in rank are Language and Cognitive Processes, Journal of Neuroscience, PNAS, and Journal of Applied Physiology. All of these are either Open Access (OA) or in full-text in Communication and Mass Media Complete after an embargo period. Knowing the exact effect of OA on use by researchers is impossible, but of interest is that $\mathrm{OA}$ is more prevalent among journals that moved up in table 4 than it is among journals that moved down in rank. However, the four journals all experienced substantial increases in the number of articles published per year, which may be a more significant factor than online availability.

Several titles decreased in rank; see table 5. The journal experiencing the greatest drop was for the blindingly obvious reason that it ceased publication. It merged into ASHA Leader, the newspaper of the American Speech-LanguageHearing Association. Three of the journals that dropped in rank published fewer articles in 2009 than in 1997: Seminars in Hearing, Language, and Annals of Neurology. Two others had no significant growth in articles published: Otology and Neurotology and Topics in Language Disorders. Decreases in rank for Archives of Neurology, Neurology, and Annals of Neurology hint at less use of general neurology journals by communication disorders researchers, but natural variability in what is cited prevents drawing any conclusions about that.

\section{Discussion}

One may conclude on the basis of the method used here that the core journals in communication disorders have changed little over a decade. But even though the list as a whole was stable, some journals did change significantly in rank. This study has several implications for collection development. One is that a core of journals carefully selected to support researchers can be expected to need only minor adjustments over time. If the case of communication disorders can be generalized to other fields, librarians can rest assured that core journals change gradually. Normal ongoing collection development activities (regrettably including cancellation projects) should be sufficient to keep the core aligned with researchers' needs.

A second implication is that collection development is somewhat easier for libraries serving a range of disciplines than it is for libraries serving a special population. A discipline like communication disorders draws from the literature 


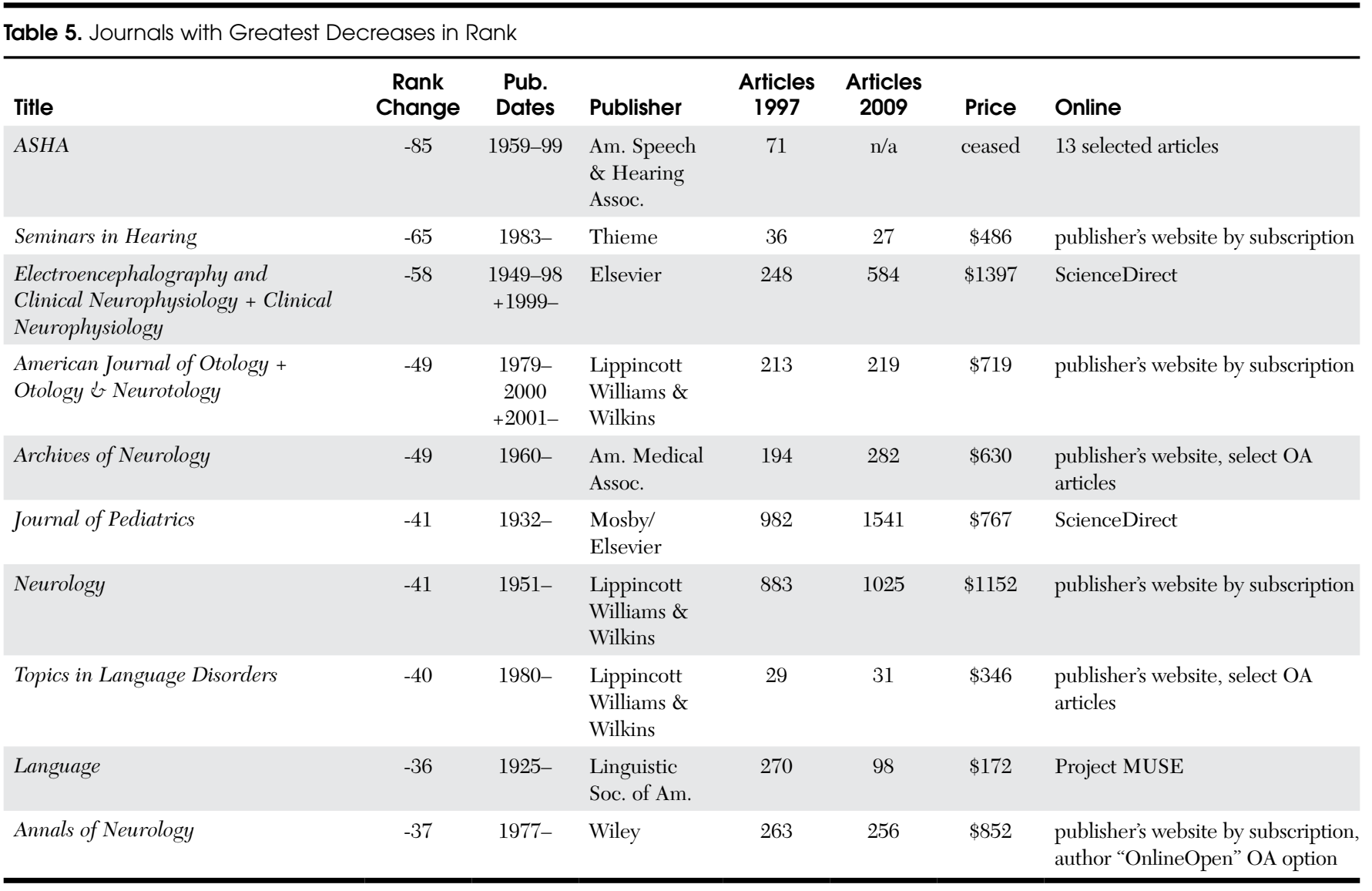

of many fields. A research library will probably have many heavily cited journals not specific to the discipline, such as Nature, Science, Cognition, and Brain. Smaller, specialized libraries are less likely to have such a broad-based collection to build upon.

A third implication is that variability in what is cited as shown in tables 2 and 3 warns librarians and scholars to treat with skepticism all ranked lists of journals. A ranked list can be a good starting point for collection development, selecting a journal to submit an article to, or suggesting appropriate places to browse. The principle of using ranks as only one source of information among many important considerations has been established in court. Judge Leonard B. Sand heard the case of publisher Gordon and Breach against Henry Barschall, who had published a ranked lists of journals based on cost relative to impact. ${ }^{45}$ Sand wrote that "[Gordon and Breach] have proved only the unremarkable proposition that a librarian would be ill-advised to rely on Barschall's study to the exclusion of all other considerations in making purchasing decisions." ${ }^{\text {"6 }}$ One should use rankings with the understanding that they have limited reliability. A different selection of sampled journal titles or years of coverage will result in a different ranked list. Rankings drawn from small samples should be treated with increased caution. Lower reliability due to a limited sample is an inherent problem with ranked lists in a subspecialty not categorized in JCR or Scopus.

\section{Limitations of Study}

A cynical interpretation of this study of core journals in communication disorders could be that the inherent unreliability of ranked lists renders it all a waste of effort. But ranked lists are still useful starting points for identifying core journals, and these data have allowed a quantified analysis of the reliability of rankings in one field. The degree to which the case of communication disorders can be generalized to other disciplines is unknown.

Although this sample size was a robust $n=15,631$ drawn from two of the most cited journals in the field, a broader selection of source journals would probably yield a ranked list that more accurately reflects the literature in communication disorders. The author was unfortunately unaware of Slater's work when he wrote the 2001 article published in LRTS ${ }^{47}$ Replicating that sample of four journals would have expanded representation of the literature and allowed direct comparisons across three time periods. The author advises anyone conducting similar research to develop the sampled 
journals in an iterative process, starting with a journal known to be a leader in the field, then expanding the selection of source journals based on preliminary rankings. A sample of at least four source journals would be superior to using only one or two.

\section{Further Research}

Additional research could investigate whether the characteristics of the journals in communication disorders discovered here can be generalized to other fields. Of particular interest is whether other disciplines' core journals experience similar reliability over time. This could be relatively easily done for disciplines categorized in JCR by a researcher with access to historical and current editions of the JCR. A fertile area for further research is to develop methods for using Google Scholar for citation analysis.

An area deserving attention is how large a sample of source journals is sufficient to yield a ranked list of a desired degree of reliability. Does one volume of one journal consistently produce a ranked list with about $r_{s}=0.65$ reliability? How small a sample is capable of identifying the top ten journals in a field with $r_{\mathrm{s}}=0.50$ reliability, or $r_{\mathrm{s}}=0.75$ ? What is the maximum attainable reliability with large samplescan any sample size attain $r_{s}=0.90$ ? Answers to questions like these would help librarians determine the degree of confidence they should have that ranked lists accurately reflect true use of the literature.

\section{Conclusions}

How reliable is a ranked list over time? The primary purpose of this study was to determine how much a ranked list of core journals changed during a decade. This was accomplished by replicating a 2001 study and calculating the Spearman's rho rank correlation coefficient of the two ranked lists. A second research question was whether variability in ranked lists was greater over time than it was among citations in source journals from the same timeframe. To answer that question, correlations were calculated to compare rankings derived from citations in two leading journals. In the process of answering those questions, discoveries were made regarding growth in literature and journals that changed most in rank were identified. This study supports these conclusions for the case of core journals in communication disorders:

- Journal literature grew substantially during the decade both in articles published and works cited per article.

- As a group, core journals remained quite stable over time $\left(r_{\mathrm{s}}=0.73\right)$.

- Despite high reliability of core journals over time, some titles changed dramatically in rank.
- Approximately one-third of change in ranked lists derived from works cited in single journal volumes is due to random variability.

The stability of a core list over time means that normal collection development activities should be sufficient to keep a collection aligned with a discipline's core of most frequently cited journals. While ranked lists are useful collection development tools, random variability in rankings cautions librarians to treat any ranked listing with some skepticism.

\section{References and Note}

1. Steve Black, "Using Citation Analysis to Pursue a Core Collection of Journals for Communication Disorders," Library Resources \& Technical Services 45, no. 1 (2001): 3-9.

2. Inna Shpilko, "An Overview of the Journal Literature on Communication Disorders," Collection Building 22, no. 3 (2003): 102-19.

3. Thomas E. Nisonger, "Journals in the Core Collection: Definition, Identification, and Applications," Serials Librarian 51, no. $3 / 4$ (2007): 51-73.

4. R. E. Rice et al., "Journal-to-Journal Citation Data: Issues of Validity and Reliability," Scientometrics 15, no. 3 (1989): 257-82.

5. Dean F. Sittig, "Identifying a Core Set of Medical Informatics Serials: An Analysis Using the Medline Database," Bulletin of the Medical Library Association 84, no. 2 (1996): 200-204.

6. Eugene Garfield, "Citation Analysis as a Tool in Journal Evaluation," Science 178 (1972): 471-79.

7. Thomson Reuters, "The Thomson Reuters Impact Factor," http://thomsonreuters.com/products_services/science/free/ essays/impact_factor (accessed Dec. 14, 2011).

8. B. R. Martin, "The Use of Multiple Indicators in the Assessment of Basic Research," Scientometrics 36, no. 3 (1996): 343-62.

9. Daniela Rosenstreich and Ben Wooliscroft, "Measuring the Impact of Accounting Journals using Google Scholar and the G-Index," British Accounting Review 41 (2009): 227-39.

10. John Hudson, "Be Known by the Company You Keep: Citations-Quality or Chance?” Scientometrics 71, no.2 (2007): 231-38.

11. Robert K. Merton, The Sociology of Science: Theoretical and Empirical Investigations (Chicago: University of Chicago Press, 1973).

12. Per O. Seglen, "Why the Impact Factor of Journals Should Not be Used for Evaluating Research," British Medical Journal 314, no. 7079 (1997): 498-502.

13. Michael H. MacRoberts and Barbara R. MacRoberts, "Problems of Citation Analysis: A Critical Review," Journal of the American Society for Information Science 40, no. 5 (1989): 342-49.

14. Stephen C. Hubbard and Marie E. McVeigh, "Casting a Wide Net: The Journal Impact Factor Numerator," Learned Publishing 24, no. 2 (2011): 133-37.

15. Bob Perdue and Chris Piotrowski, "Citation Searching: A 
New Feature in PsycINFO," Perceptual \& Motor Skills 96 (2003): 1237-38.

16. Katherine W. McCain, "Core Journal Networks and Cocitation Maps: New Bibliometric Tools for Serials Management," Library Quarterly 61, no. 3 (1991): 311-36.

17. Jeffery D. Kushkowski, Kristin H. Gerhard, and Cynthia Dobson, "A Method for Building Core Journal Lists in Interdisciplinary Subject Areas," Journal of Documentation 54, no. 4 (1998): 477-88.

18. Thura Mack, “A Model Methodology for Selecting Women's Studies Core Journals," Library \& Information Science Research 13 (1991): 131-45.

19. Dean F. Sittig, "Identifying a Core Set of Medical Informatics Serials: An Analysis Using the Medline Database," Bulletin of the Medical Library Association 84, no. 2 (1996): 200-204.

20. David A. Goss, "Citation Patterns in the Optometric and Ophthalmologic Clinical Binocular Vision Literature," Optometry \& Vision Science 83, no. 12 (2006): 895-902.

21. Christina C. Wray, "The Journey Starts Here: Finding Special Education Research in Subscription Databases," Reference Librarian 52 (2011): 231-43.

22. Linda G. Slater, "Mapping the Literature of Speech-Language Pathology," Bulletin of the Medical Library Association 85, no. 3 (1997): 297-302.

23. Anne-Wil Harzing and Ron van der Wal, "A Google Scholar H-Index for Journals: A Better Metric to Measure Journal Impact in Economics and Business?" (paper submitted to the 2008 Academy of Management Annual Meeting August 8-13, 2008, Anaheim, California).

24. S. C. Bradford, "Sources of Information on Specific Subjects," Engineering 137 (1934): 85-86.

25. P. Nieuwenhuysen and R. Rousseau, "A Quick and Easy Method to Estimate the Random Effect on Citation Measures," Scientometrics 13, no. 1/2 (1988): 45-52.

26. Maurice B. Line, "Use of Citation Data for Periodicals Control in Libraries: A Response to Broadus," College d Research Libraries 46, no. 1 (1985): 36.

27. Maurice B. Line, "Changes in Rank Lists of Serials Over Time: Interlending versus Citation Data," College \& Research Libraries 46, no. 1 (1985): 77-79.

28. Robert N. Broadus, "A Proposed Method for Eliminating Titles from Periodical Subscription Lists," College \& Research Libraries 46, no. 1 (1985): 30-35.

29. Ibid.

30. John Laurence Kelland and Arthur P. Young, "Citation as a
Form of Library Use," Collection Management 19, no. 1/2 (1994): 81-100.

31. Murray J. White and K. Geoffrey White, "Citation Analysis of Psychology Journals,” American Psychologist 32, no. 5 (1977): 3015.

32. Rick Ralston, Carole Gall, and Frances A. Brahmi, "Do Local Citation Patterns Support Use of the Impact Factor for Collection Development?" Journal of the Medical Library Association 96, no. 4 (2008): 374-78.

33. Janice Kreider, "The Correlation of Local Citation Data with Citation Data from Journal Citation Reports," Library Resources \& Technical Services 43, no. 2 (1999): 67-77.

34. Stephen J. Bensman, "Probability Distributions in Library and Information Science: A Historical and Practitioner Viewpoint," Journal of the American Society for Information Science \& Technology 51, no. 9 (2000): 816-33.

35. S. C. Bradford, "Sources of Information on Specific Subjects."

36. Sidney Siegel, "Nonparametric Statistics," American Statistician 11, no. 3 (1957): 13-19.

37. Maurice Kendall and Jean Gibbons, Rank Correlation Methods, 5th ed. (New York: Oxford Univ. Pr., 1990).

38. Merriam-Webster, "Reliability," www.merriam-webster.com/ dictionary/reliability (accessed Dec. 21, 2011).

39. Linda G. Slater, "Mapping the Literature of Speech-Language Pathology."

40. Black, "Using Citation Analysis to Pursue a Core Collection of Journals for Communication Disorders," 6.

41. Murray R. Spiegel, Schaum's Outline of Theory and Problems of Statistics (New York: Schaum, 1961): 73.

42. Black, "Using Citation Analysis."

43. Slater, "Mapping the Literature of Speech-Language Pathology."

44. Line, "Use of Citation Data."

45. See Gordon and Breach v. American Institute of Physics and American Physical Society, http://barschall.stanford.edu (accessed Dec. 14, 2011) for a thorough and well organized treatment of the Gordon and Breach case against Barschall and the publishers of his studies.

46. Gordon and Breach v. American Institute of Physics and American Physical Society, 973 F. Supp. 414 (U.S. District Court for Southern New York), Aug. 26, 1997, http:// barschall.stanford.edu/opinions/970826OPIN.html (accessed Dec. 14, 2011).

47. Slater, "Mapping the Literature of Speech-Language Pathology." 


\section{Appendix. Core Journals in Communication Disorders Based on Times Cited 2007-9 $(N=15,631)$}

\section{Title}

Journal of Speech, Language, \& Hearing Research + Journal of Speech \& Hearing Research + Journal of Speech b Hearing Disorders

Journal of the Acoustical Society of America

Journal of Communication Disorders

Journal of Child Language

Ear \& Hearing

Journal of Fluency Disorders

Journal of Child Psychology \& Psychiatry + Journal of Child Psychology \& Psychiatry \& Allied Disciplines

Brain \& Language

British Journal of Disorders of Communication + European Disorders of Communication +

International Journal of Language \& Communication Disorders

Journal of Voice

Child Development

American Journal of Speech-Language Pathology

Applied Psycholinguistics

Clinical Linguistics \& Phonetics

Language, Speech, \& Hearing Services in Schools

Cognition

Developmental Psychology

Journal of Autism \& Developmental Disorders

Journal of Phonetics

Journal of Memory \& Language

Hearing Research

Folia Phoniatrica + Folia Phoniatrica et Logopaedica

Annals of Otology, Rhinology, \& Laryngology

Journal of the American Academy of Audiology

Science

Journal of Applied Physiology

Journal of Experimental Child Psychology

Brain

Trends in Cognitive Sciences

Language \& Speech

Dysphagia

Nature

Psychological Review

Laryngoscope

Acta Otolaryngologica

Journal of Neurophysiology

Aphasiology

Developmental Medicine \& Child Neurology

Perceptual \& Motor Skills

Neuropsychologia
$\%$ of

Cites

$\triangle$ Rank since

1999

16.25

0

6.74

1.52

0

$+3$

1.49

1.44

1.38

1.24

1.20

1.17

1.17

1.07

1.06

0.99

0.92

0.92

0.86

0.75

0.75

0.74

0.69

0.63

0.61

0.59

0.57

0.55

0.47

0.46

0.45

0.45

0.44

0.44

0.44

0.44

0.41

0.41

0.41

0.40

0.36

0.35

0.35 


\section{Appendix. Core Journals in Communication Disorders Based on Times Cited 2007-9 ( $N=15,631)$ (continued)}

Title

Journal of Medical Speech-Language Pathology

Cites

$\triangle$ Rank since

1999

Perception \& Psychophysics

0.34

$+63$

Journal of Neuroscience

0.33

$-17$

Language \& Cognitive Processes

0.32

$+57$

Memory \& Cognition

0.31

$+60$

Psychological Bulletin

0.30

$+30$

Cleft Palate Journal + Cleft Palate-Craniofacial Journal

0.30

0.29

$+6$

Cognitive Psychology

0.29

Journal of Experimental Psychology: Human Perception \& Performance

Pediatrics

Augmentative \& Alternative Communication

Cortex

Proceedings of the National Academy of Sciences of the United States of America

Archives of Otolaryngology + Archives of Otolaryngology —Head \& Neck Surgery

Audiology

Journal of Experimental Psychology: Learning, Memory, \& Cognition

Journal of Learning Disabilities

NeuroImage

0.27

British Journal of Audiology

Journal of Verbal Learning \& Verbal Behavior

Topics in Language Disorders

Phonetica

Seminars in Speech \& Language

Monographs of the Society of Research in Child Development

Speech Communication

Experimental Brain Research

Journal of Educational Psychology

Psychological Science

Developmental Science

Quarterly Journal of Experimental Psychology

Scandinavian Audiology

Developmental Neuropsychology

First Language

International Journal of Audiology

Journal of Cognitive Neuroscience

Journal of the American Academy of Child \& Adolescent Psychiatry

0.21

Infant Behavior \& Development

Journal of Experimental Psychology: General

Volta Review

0.20 


\section{Appendix. Core Journals in Communication Disorders Based on Times Cited 2007-9 ( $N=15,631)$ (continued)}

\begin{tabular}{|c|c|c|}
\hline Title & $\begin{array}{l}\% \text { of } \\
\text { Cites }\end{array}$ & $\begin{array}{c}\Delta \text { Rank since } \\
1999\end{array}$ \\
\hline Behavioral \& Brain Sciences & 0.19 & +23 \\
\hline American Journal of Audiology & 0.18 & -11 \\
\hline American Journal of Human Genetics & 0.18 & +18 \\
\hline Brain Research & 0.18 & +6 \\
\hline Journal of Psycholinguistic Research & 0.18 & -31 \\
\hline Language Acquisition & 0.18 & -18 \\
\hline Neuroreport & 0.18 & +18 \\
\hline Reading \& Writing: An Interdisciplinary Journal & 0.18 & +18 \\
\hline Archives of Physical Medicine \& Rehabilitation & 0.17 & +14 \\
\hline Reading Research Quarterly & 0.17 & +14 \\
\hline American Journal of Mental Retardation & 0.16 & -8 \\
\hline Cognitive Development & 0.16 & +11 \\
\hline Journal of Neurology, Neurosurgery, \& Psychiatry & 0.16 & -1 \\
\hline American Journal of Medical Genetics & 0.16 & -4 \\
\hline Electroencephalography \& Clinical Neurophysiology + Clinical Neurophysiology & 0.16 & -58 \\
\hline American Journal of Otology + Otology \& Neurotology & 0.15 & -49 \\
\hline American Journal of Psychiatry & 0.15 & +4 \\
\hline International Journal of Pediatric Otorhinolaryngology & 0.15 & +4 \\
\hline Journal of Neurolinguistics & 0.15 & +4 \\
\hline Lancet & 0.15 & +4 \\
\hline Lingua & 0.15 & +4 \\
\hline Neuroscience Letters & 0.15 & +4 \\
\hline Annals of Dyslexia & 0.14 & -18 \\
\hline
\end{tabular}

